\title{
Research on the Risk Management Issues of VAM Agreements in Private Equity Financing
}

\section{Cong Du*}

Lanzhou University of Technology School of Economics and Management, Lanzhou 730050, China

*Corresponding author: Cong Du, DC18394515428@163.com

Copyright: (C) 2022 Author(s). This is an open-access article distributed under the terms of the Creative Commons Attribution License (CC BY 4.0), permitting distribution and reproduction in any medium, provided the original work is cited.

\begin{abstract}
At present, the biggest obstacle that growing enterprises may encounter in their development process is insufficient funds. Private equity financing does not only solve the capital problem of enterprises, but also provide enterprises with professional management concepts and even help growing enterprises to go public in advance. However, high returns must be accompanied by high risks. For example, private equity financing has information asymmetry risks, principal-agent risks, etc., and these risks make it impossible to maximize the advantages of private equity financing. Therefore, in order to reduce the risks brought by financing, investment and financing parties should choose to sign gambling contracts to reduce the risk. In recent years, the use of VAM agreements has become more in China. However, according to incomplete statistics, less than $30 \%$ of VAM agreements are successful, and this result is mainly due to the insufficient depth and breadth of research on VAM agreements. Therefore, this article will comprehensively analyze the problems that need to be paid attention to when signing a gambling agreement by introducing the case of Anda Technology, and the issue of targeted risk prevention will also be discussed in this paper.
\end{abstract}

Keywords: Private equity financing; Gambling agreement; VAM agreement; Risk prevention and control

Online publication: February 28, 2022

\section{Introduction}

In the current environment, financing difficulties and high financing costs are the financial difficulties faced by most small and medium-sized enterprises ${ }^{[1]}$. Under such circumstances, enterprises have begun to turn their attention to the capital market. At the same time, with the accelerated growth of China's capital market, private equity financing has gradually become a financing channel for the majority of private enterprises ${ }^{[2]}$. However, with the development of private equity financing, the disadvantages of private equity financing have gradually emerged. For example, there are obvious information asymmetry risks and principal-agent risks in private equity financing. In order to accurately determine the financing amount in private equity financing, investors need to measure the value of the financing company; however, the valuation of the financing company is affected by the information asymmetry between the two parties ${ }^{[3]}$. Therefore, it is difficult for the investment and financing parties to reach an agreement on the valuation of the company. In order to solve this drawback, the two parties will sign a VAM agreement, which stipulates that the valuation of the financing company can be adjusted in the later stage. With VAM agreements, investors can design a guarantee mechanism to protect their own interest, and it is then possible to reach the right effect of financier incentives ${ }^{[4]}$. Although VAM has been widely used in private equity financing, not all VAM agreements can achieve a win-win situation. On the contrary, most VAM agreements end in failure. Many gambling agreements fail due to other external factors or the failure of the set gambling 
performance in meeting certain standards ${ }^{[5]}$. Therefore, the issue of how to better use the VAM protocol and take precautions against the risks that may occur during the use of the VAM protocol is very important. Private equity financing and VAM agreements will play increasingly important roles in more financing activities in the future ${ }^{[6]}$.

\section{Related concepts}

\subsection{The connotation of private equity financing}

Private equity financing refers to the handover of funds to equity investment managers by specific subjects, such as companies and their individuals, or other financiers for management and investment in a non-public way. Investment managers invest in unlisted companies for equity financing, thereby relying on business operations to obtain premium income ${ }^{[7]}$.

\subsection{Participants in private equity financing}

Private equity financing is mainly composed of three parts: investors, financiers, and intermediaries ${ }^{[8]}$. Financiers refer to financing enterprises, and traditional private equity financiers mainly refer to growing private enterprises that have potential ${ }^{[9]}$. Investors mainly refer to large enterprises, including institutional investors and wealthy people ${ }^{[10]}$. Among the investors, institutional investors account for the majority. Most of the intermediaries refer to fund managers or fund companies. Fund managers, as unlimited partners, assume unlimited responsibilities in private financing. This helps to curtail the extreme information asymmetry that may be caused by the financing process and solve the corresponding incentive mechanism problem ${ }^{[11]}$.

\subsection{The concept of VAM agreement}

Valuation adjustment mechanism (VAM) refers to an agreement that is designed to reach a private equity financing agreement as it is difficult for both, investment and financing parties to make a 100 percent correct judgment on the actual situation of the future development of the financing company ${ }^{[12]}$. The agreement stipulates that the investment can be adjusted according to the actual operation of the enterprise in the future [13]. While alleviating the information asymmetry between investment and financing parties, the VAM agreement can also form an incentive mechanism for financiers ${ }^{[14]}$. In terms of corporate valuation, investors inevitably use less information on the operation of financing companies than financiers, and at the same time, it is difficult for investors to fully understand the actual investment value of financiers through other channels. The agreement can alleviate this information asymmetry risk ${ }^{[15]}$. Through this agreement, it is then possible to agree on terms that will come into effect conditionally based on the business performance over a period of time and define the obligations and rights established by both parties. In this way, the investment risk can be reduced, and the profitability and safety of investors will improve. In addition, the VAM agreement can motivate the management of the financing company because the value of the agreement ultimately depends on the improvement of the financing company's management level ${ }^{[17]}$. Therefore, the agreement plays an incentive role for financing companies, and in foreign private equity financing, gambling agreements are also commonly used to incentivize management ${ }^{[18]}$.

\subsection{Components of VAM agreement}

The main components of the gambling agreement include the gambling subject, the gambling standard, and the gambling object. The subjects are the participants who sign the gambling agreement, including investors and financiers. As VAM agreements are not widely used in China, most investment institutions with 
overseas background are the investors who sign these agreements, and there are only a small number of investment institutions with financial strength in China. Another signing entity is the financier. Most of the financiers in China are start-up private enterprises. There are many enterprises with great development potential. These enterprises are rapidly developing, but they lack funds; in addition, the traditional financing channels are relatively inferior. There are also many financing obstacles, so it is important for these enterprises to rely on investment institutions for financing.

The VAM standard refers to the evaluation and judgment criteria for VAM. It refers to the crux that triggers the VAM agreement to function. The standard of gambling mainly includes non-financial performance, financial performance, the whereabouts of management, stock issuance, redemption compensation for corporate behavior, and so on. There are many indicators of financial performance, including operating income and net profit growth rate; the indicators of non-financial performance include sales volume, output, research and development (R\&D) technology, market share, etc.; corporate behavior includes horizontal competition, illegal crimes, affiliated transactions, etc.; stock issuance refers to the main board listing, listing on the New Third Board, etc.; redemption compensation refers to the repurchase of preferred shares. When financial performance is used as the standard, investors generally have the following three choices: the first is based on a single objective, such as the quarterly profit or pre-tax profit index, as the condition for equity changes; the second is based on a single target, in which a series of step-by-step standards will be set up, and each time a standard is reached, the equity will change to a certain degree; the third is to set the upper and lower bounds as long as the change of equity can be realized between the upper and lower bounds. At present, the VAM standard applied to VAM agreements in China is still mainly based on financial indicators.

The gambling object is the bet, in which most of the bet is based on option subscription, investment amount, and equity. If the operating performance of the financing company reaches the target set in the VAM clause, the investor will transfer a certain equity stake to the management of the financing company at a lower price or even for free; otherwise, the management of the financing company will directly obtain part of the option subscription. On the contrary, if the financing company does not meet the set standards, the management needs to purchase the equity held by the investor at a higher price or transfer a certain option subscription right, thus increasing the investor's financing and the seats on corporate boards.

\section{Case discussion}

\subsection{Financing party}

Guizhou Anda Technology and Energy Co., Ltd., also known as Anda Technology, was incorporated on August 23, 1996. At the time of its establishment, it mainly engaged in the production of traditional businesses, such as phosphoric acid and yellow phosphorus; however, the pressure of development faced by traditional businesses was increasing. By looking for a new way to solve this issue, Anda Technology gradually took on the role of an enterprise that engages in the new energy industry. In 2006, Anda Technology had not yet been upgraded and transformed, but it was able to complete the annual production of high-yield phosphoric acid and sodium tripolyphosphate. At the same time, affected by the country's continuous implementation of industrial structural upgrading, energy conservation, and emission reduction policies, as well as the transformation and upgrading of global industries, Anda Technology proposed a ten-year development plan in 2009 to cope with the pressure. The goal of industrial transformation and upgrading has been set as its development direction, while technological innovation is assumed as the core competitiveness of enterprises by Anda Technology. Taking advantage of the policy situation related to the improvement of China's new energy industry, Anda Technology came to actualize spinoff businesses in 2013 and successfully completed the reform work pertaining to shares. Anda Technology also landed on the New Third Board in the second year acceding the new energy theme. 


\subsection{Investors}

The investors who contributed are Jiaxing Chunqiu Chuzhuang Jiuding Investment Center (hereinafter, referred to as Chuzhuang Jiuding), Jiaxing Chunqiu Jinwen Jiuding Investment Center (hereinafter, referred to as Jinwen Jiuding), Jiaxing Chunqiu Qiheng Jiuding Investment Center (hereinafter, referred to as Qiheng Jiuding), and Suzhou Jiaying Jiuding Investment Center (hereinafter, referred to as Jiaying Jiuding). A total of four four-share equity funds participated, with a joint investment of 154.3 million yuan. These four investment institutions belong to Kunwu Jiuding Investment Holdings Co., Ltd. (hereinafter, referred to as Jiuding Investment). Jiuding Investment currently has three main businesses, including real estate investment, private equity investment, and fixed income. There are professional teams in most fields.

\section{Gambling agreement}

\subsection{Contents of gambling agreement}

In the gambling agreement, the first clause is performance compensation. Jiuding Investment required Anda Technology to deliver a net profit of more than 8 million yuan in 2011, 20 million yuan in 2012, and 30 million yuan in 2013. In 2014, it should not be less than 40 million yuan. If one of the four years does not meet the performance standard, Anda Technology or Party $\mathrm{C}$ would be required to pay Party A cash compensation. The amount of cash compensation in each year = Party A's investment * $(1-$ actual achieving performance / promised performance indicators).

The second clause is the exit arrangement. In the case of Anda Technology and Jiuding Investment, Jiuding Investment made the following clauses when signing the VAM agreement: if Anda Technology wants to liquidate, then Anda Technology must pay the taxes owed; when the company's debts are paid off and Party B's remaining assets are distributed, Party B and Party C must ensure that Party A obtains all the investment in Party B plus additional payment, which is part of the dividends that Party B has announced but has not implemented yet; if the remaining assets distributed by Anda Technology to Party A are less than the above amount, then the insufficient part should be obtained by Party $\mathrm{C}$ according to the liquidated assets to compensate Jiuding Investment.

The third clause is the supplementary agreement. On January 23, 2014, Party A, Party B, and Party C signed a supplementary agreement, the Supplementary Agreement II on the Capital Increase and Share Expansion Agreement of Kaiyang Anda Phosphorus Chemical Co., Ltd. in Guizhou Province. This supplementary agreement does not have any impact on the validity of the relevant capital increase agreement and the supplementary agreement signed by all parties. According to the agreement, ever since the application of Anda Technology for listing, Jiuding Investment has temporarily waived the investigation of Anda Technology to assume joint and several liability, pay the corresponding performance compensation, and give up the requirement for Party B and Party $\mathrm{C}$ to transfer or repurchase the shares of Anda Technology in the hands of Jiuding Technology. However, Jiuding Technology can still request Party B and Party C to pay the corresponding performance compensation.

\subsection{Results of betting}

According to the WIND database, the net profits of Anda Technology in 2012-2014 did not meet the set gambling performance standards (Table 1). 
Table 1. Anda Technology's net profit from 2012 to 2014

\begin{tabular}{cccc}
\hline Year & Actual net profit (RMB) & Performance requirements (RMB) & Compliance \\
\hline 2012 & 698,0575 & $20,000,000$ & No \\
2013 & $-4,438,643$ & $30,000,000$ & No \\
2014 & $16,361,358$ & $40,000,000$ & No \\
\hline
\end{tabular}

Data source: WIND database

From Table 1, it can be seen that although the actual net profit of Anda Technology from 2012 to 2014 did not meet the performance standards required by Jiuding Investment, the Supplementary Agreement II on the Capital Increase and Share Expansion Agreement of Kaiyang Anda Phosphorus Chemical Co., Ltd. in Guizhou Province pointed out that from the day of reporting the listing materials to the National Equities Exchange and Quotations, Jiuding Investment will temporarily give up on pursuing Anda Technology to assume joint responsibility and pay the corresponding performance compensation as well as in requiring Party B and Party C to transfer or repurchase Anda Technology from Jiuding Technology. However, Jiuding Technology can still request Party B and Party $\mathrm{C}$ to pay the corresponding performance compensation. Anda Technology was successfully listed on the New Third Board in 2014. At the same time, the net profit of Anda Technology in 2016 after the listing increased significantly. In the 2016 intermediate report, three Jiuding investment companies, Jinwen Jiuding, Chuzhuang Jiuding, and Jiaying Jiuding, held a total of 18,220,184 shares of the financier, but in the 2016 annual report, Jiuding Investment was not listed as one of the top ten shareholders of Anda Technology. From the 2,815,000 shares held by the tenth shareholder, Zhu Qingfeng, Jiuding Investment sold at least 9,775,184 shares of Anda Technology in the second half of 2016. The average transaction price of the stock in half a year is 19.85 yuan. Party A could have at least earned 194 million yuan and a maximum of 362 million yuan in profit in that half-year. It can be seen from the above results that although Anda Technology did not achieve the net profit target, it was successfully listed in the end, making both parties profitable. Therefore, the bet between Anda Technology and Jiuding Investment was considered successful.

\section{Anda Technology's gambling risk analysis}

\subsection{External macro environment}

When the external environment of an industry is in a relatively unstable state, it will lead to uncertainties in the future direction of the market, so the possibility of failure in the gamble is higher. Therefore, analyzing the external environment is crucial. Since July 2012, China has promulgated a series of relevant policy plans for the new energy automobile industry, which have laid the foundation for the development of new energy automobiles and provided policy support. The State may subsidize the sales of certain products in the new energy automobile industry in the future. This will also affect the development of other industries related to this industry. The main products of Anda Technology include lithium-ion batteries for new energy automobiles as well as iron phosphate and lithium iron phosphate battery materials. Its production is directly affected by the promotion of national policies. The development scale of lithium batteries in China from 2012 to 2015 is shown in Figure 1. 


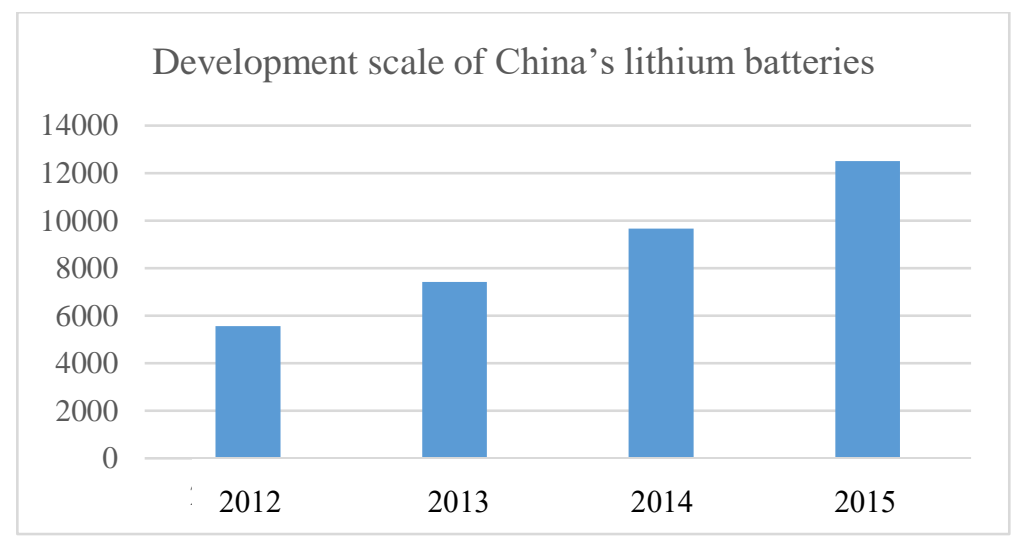

Figure 1. Development scale of China's lithium batteries

By analyzing Figure 1, from the perspective of the external macro environment of lithium batteries, Anda Technology is facing opportunities along with risks and challenges. The company must improve its competitive advantage and seize opportunities, so as to improve its corporate performance and the probability of success of the gambling agreement.

\subsection{Performance commitment setting}

The level of performance commitment is positively related to the difficulty of realizing the agreement. If the level of performance commitment is higher, it will naturally be more difficult for the company to achieve the performance standard and to realize the VAM agreement. If Anda Technology plans to achieve a net profit of 40 million yuan in 2014, it means that its' compound growth rate in three years must reach $71 \%$, but in fact, its' annual growth rate since the signing of the agreement has not been ideal. In 2013, the net profit became negative. Although it finally achieved a great increase in net profit in 2014, its overall compound annual growth rate was only $53.1 \%$, lower than the expected $71 \%$ (Table 2 ). This shows that the average annual growth rate required of Anda Technology in terms of net profit by the performance requirements is too high as it is inconsistent with the average annual growth rate in the industry itself.

Table 2. Comparison of the actual net profit and expected performance standard of Anda Technology in 2011-2014

\begin{tabular}{cccccc}
\hline Year & 2011 & 2012 & 2013 & 2014 & Compound growth rate \\
\hline Anda Technology (actual) & - & 698 & -444 & 1,636 & $53.1 \%$ \\
Anda Technology (expected) & 800 & 2,000 & 3,000 & 4,000 & $71 \%$ \\
\hline
\end{tabular}

Data source: WIND database

\subsection{Enterprise valuation}

There are various methods for evaluating the value of an enterprise, but the obtained value from each method is not indistinguishable. At present, the cost method, the income method, and the market method are more recognized. These three methods have their own advantages and disadvantages. At present, there is no single evaluation method that can combine the advantages of these three methods.

In the betting between Anda Technology and Jiuding Investment, from the analysis of the commitment terms set above, it can be seen that the performance of the bet is far from the actual performance. Jiuding Investment's valuation of Anda Technology is not completely accurate. In the actual process of signing the agreement, a combination of the market method and the income method was used. However, the market 
method requires an open and active market, so that the valuation made on this premise can objectively reflect the asset's current market conditions. The disadvantages of the income method include the requirement of forecasts of future earnings and discount rates. In addition, both methods must rely on the subjective judgment of the evaluator; thus, it is impossible to guarantee the objectivity of the results.

\subsection{Financier's performance capability}

Many investors take the initiative to sign VAM agreements mainly because these agreements can reduce the risks caused by incomplete contracts and information asymmetry. It is expected that the risk can be controlled within a certain range by signing such an agreement. If the commitment standard is met, the investor can also be compensated accordingly. However, many investors often disregard the question of whether the financier has the ability to fulfill the compensation. In consideration of the incomplete historical data of Anda Technology before 2012, this study analyzes its VAM agreement based on the current ratio, quick ratio, equity ratio, and asset turnover ratio of Anda Technology over three years from 2012 to 2014 (Table 3).

Table 3. Anda Technology's solvency indicators in 2012-2014

\begin{tabular}{cccc}
\hline Year & 2012 & 2013 & 2014 \\
\hline Current ratio & 1.62 & 2.42 & 2.14 \\
Quick ratio & 0.75 & 0.91 & 0.69 \\
Asset turnover ratio & 0.72 & 0.78 & 1.36 \\
Equity ratio & 0.78 & 0.40 & 0.58 \\
Interest coverage ratio & 0.84 & -5.12 & 3.63 \\
\hline
\end{tabular}

Data source: WIND database

Generally speaking, if the current ratio is around two, it means that the liquidity is good. From Table 3, it can be seen that the current ratio of Anda Technology was lower than 2 in 2012 and higher than 2 in 2013 and 2014. According to the indicators, Anda Technology has strong solvency, but the quick ratios over the three years were relatively low, all below 1, indicating that the financing company has a large inventory scale and a slow inventory turnover. This reflects that the company has realized cash flow. The ability is relatively weak, which leads to the weakening of its actual short-term debt repayment ability. From the perspective of long-term debt repayment ability, the asset turnover ratios in 2012 and 2013 were lower than 0.8 , but in 2014, it was as high as 0.8 (1.36). Therefore, from an overall point of view, the asset turnover over the three years is acceptable. The property rights ratios of Anda Technology over the three years were lower than 1 . Therefore, it can be inferred that the proportion of non-self-owned capital of Anda Technology to the total capital is relatively small. It can be seen that the company's asset structure is relatively reasonable. Overall, Anda Technology's short-term solvency is weak, but its long-term solvency is strong.

\section{Risk prevention and control of gambling agreements}

\subsection{Macro environment}

Investment and financing companies should pay attention to the following aspects when conducting market and industry analyses: (1) pay attention to the macro environment, such as industry policies, make reasonable expectations for the future development of financing companies, and analyze contingencies and uncertainties; (2) investors should strengthen their understanding of the industry in which the company 
focuses on, and both investors and financing parties should pay more attention to competitors in the industry; (3) strategically pay attention to product pricing strategies, product lines, and sales channels.

\subsection{Setting reasonable gambling standards}

Investment and financing parties should reasonably compare and analyze the risks caused by the betting target and the economic benefits brought about by the future development of the financing company. The two parties should negotiate properly when signing the contract. The investor should not make a higher performance commitment due to capital, and the financier should not accept the investor's funds or unreasonable gambling chips, which increases the gambling risks of the enterprise on the road to development. For example, Liujing Technology and Jingjia Investment set higher gambling indicators, which led to the financier, Liujing Technology, to bear greater risks, resulting in the irrational expansion of Liujing Technology in its development. This is not conducive to the development of the enterprise in the future. Therefore, companies must analyze their past performance and current performance in a comprehensive manner, and at the same time consider the changes in the external macro environment as well as the impact of policies on the industry to rationally judge the company's future business performance. Enterprises are caught in a situation where the betting performance is too high, which results in failure.

\subsection{Setting up multiple betting indicators, and integrating financial and non-financial standards}

Anda Technology does not only set financial standards, but also standards for companies to go public, which is conducive to the long-term development of the company. Blindly expanding just for short-term net profit will not be the case for Anda Technology. However, Liujing Technology only sets financial performance standards, thus focusing on main business income and net profit, which will not be conducive to the long-term development of the enterprise or the improvement of internal governance and management capabilities as the management will only pay attention to the improvement of the enterprise's operating performance in the process of development. Therefore, financing companies must set multiple indicators when signing a VAM agreement and integrate financial with non-financial standards, so that the the longterm development of the company is not neglected in the pursuit of performance growth.

\subsection{Investing companies evaluate the value of financing companies}

Both investment and financing parties should select a reasonable and effective evaluation method. With different assessment methods, considering the advantages and disadvantages of the methods and combining them with the application of the gambling agreement can ensure the acquisition of accurate and complete data and parameters as well as the accuracy of value prediction and evaluation, so as to obtain the financial data of the financing enterprise and to fully analyze whether the financing enterprise has sufficient performance capacity.

\subsection{Investing companies provide mature management concepts for financing companies}

After signing the VAM agreement, the financing enterprise must not only realize the VAM standard, but also improve the management ability of the enterprise from the perspective of long-term interests, so as to ensure the long-term stability and healthy development of the enterprise. In order to improve the operation and management capabilities of enterprises, first of all, financing enterprises must improve their core competitiveness and grasp the competitive advantages in the industry. At the same time, they should formulate future development plans according to their own development scale and other conditions in line with the changes in the macro environment and their strategic goals. Secondly, investors must provide financiers with mature management concepts and operating experiences. They should also establish unified 
strategic partnerships with financiers, help financiers to standardize company management systems, improve corporate governance structures, promote strategic planning, improve the supervision and management of financiers, and enhance the investment value of financiers.

\section{Disclosure statement}

The author declares no conflict of interest.

\section{References}

[1] Gilson RJ, 1984, Value Creation by Business Lawyers: Legal Skills and Asset Pricing. The Yale Law Journal, 94(2): 239-313.

[2] Brander JA, Amit R, Antweiler W, 2002, Venture-Capital Syndication: Improved Venture Selection Vs. the Value-Added Hypothesis. Journal of Economics \& Management Strategy, 11(3): 423-452.

[3] Gadman BD, Carrizosa R, Faurel L, 2014, Economic Determinants and Information Environment Effects of Earnouts: New Insights form SFAS 141(R). Journal of Accounting Research, 52(1): 37-74.

[4] Zhou C, 2009, Private Equity Financing, VAM Agreement and Path Dependence of Financial Performance of Growth Enterprises. Academic Research, 2009(09): 89-93.

[5] Luo Q, 2009, Gambling Agreement: Connotation, Risk Benefit and Decision-Making Model. Zhejiang Finance, 2009(06): 37-38.

[6] Cheng J, Cheng F, 2007, The Application of "Gambling Agreement" in Chinese Enterprises. China Management Informatization (Comprehensive Edition), 2007(05): 49-50.

[7] Mi Y, 2009, Gambling Agreements in Corporate Financing: Incentive and Risk Analysis. Economic Research Guide, 2009(36): 118-120.

[8] Gao M, 2013, How to Achieve a Win-Win Situation for Gambling Agreements. Contemporary Economy, 2013(21): 132-133.

[9] Cain MD, Denis DJ, Denis DK, 2011, Earnouts: A Study of Financial Contracting in Acquisition Agreements. Journal of Accounting Economics, 51(1-2): 151-70.

[10] Liu J, Li Q, Yan J, 2019, The "Gambling Trap" Behind the Reorganization - An Analysis of the Financial Fraud Case of Yabaite. Finance and Accounting Monthly, 2019(07): 44-48.

[11] Liu L, Gao G, Xie X, 2019, Risks and Prevention of Corporate Mergers and Acquisitions Gambling from a Financial Perspective: Taking Gaosheng Holdings' Merger and Acquisition of Yingyue Network as an Example. Finance and Accounting Communications, 2019(35): 103-105.

[12] Li J, 2011, Legal Risk Prevention of Chinese Enterprises Signing VAM Agreements. Law Journal, 32(09): 133-135.

[13] Du K, 2017, Qualitative and Feasibility Study of Private Equity VAM Agreement - Based on Theoretical Interpretation and Case Analysis. Southwest Finance, 2017(08): 30-35.

[14] Kohers N, Ang J, 2000, Earnouts in Mergers: Agreeing to Disagree and Agreeing to Stay. The Journal of Business, 73(3): 445-476.

[15] Yue X, 2017, Risk Analysis of Frequent Mergers and Acquisitions by Listed Companies in my Country: Taking Blue Cursor as an Example. Finance and Accounting Monthly, 2017(16): 96-101.

[16] Zhang K, 2018, Research on Risk Management of VAM Agreements in Equity Investment. Economic Issues, 2018(08): 53-59. 
[17] Freund JC, 1988, Mergers and Acquisitions: The Quintessence of Change. Clev St L Rev, 1988(36): 495.

[18] Gu Y, Zhang M, 2018, Research on Risk Prevention and Control of Gambling Agreement in Private Equity Financing - Taking LJ Company as an Example. Accounting Learning, 2018(26): 211-212.

Publisher's note

Bio-Byword Scientific Publishing remains neutral with regard to jurisdictional claims in published maps and institutional affiliations. 